\title{
Hypertension prevalence in obstructive sleep apnoea and sex: a population-based case-control study
}

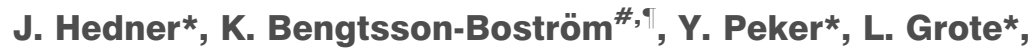 \\ L. Råstam ${ }^{\#}$ and U. Lindblad ${ }^{\#, \oplus \mid}$
}

ABSTRACT: Obstructive sleep apnoea (OSA) is a recognised risk factor for hypertension (HT). The current authors investigated confounders of this association in a sex-balanced communitybased sample of patients with HT $(n=161)$ from the Skaraborg Hypertension and Diabetes Project $(n=1,149)$ and normotensive controls $(n=183)$ from an age and sex stratified community-based population sample $(n=1,109)$. All participants underwent ambulatory home polysomnography.

Severe OSA (apnoea-plus-hypopnoea index $(\mathrm{AHI}) \geqslant 30$ events $\cdot h^{-1}$ ) was found in 47 and $25 \%$ of hypertensive and normotensive males, respectively. The corresponding numbers in females were 26 and 24\%, respectively. The odds ratio (OR) for HT increased across AHI tertiles from 1.0 to 2.1 (95\% confidence interval: $0.9-4.5)$ and 1.0 to 3.7 (95\% Cl: 1.7-8.2) in males, but not in females where the OR increased from 1.0 to 1.8 (95\% Cl: $0.8-3.9)$ and 1.0 to 1.6 (95\% Cl: $0.7-3.5)$. Regression analysis correcting for age, body mass index (or waist-hip ratio) and smoking did not eliminate the association between OSA and HT in males.

The present data suggest that obstructive sleep apnoea is highly prevalent in both the general population and in patients with known hypertension. The contribution of obstructive sleep apnoea to hypertension risk may be sex dependent and higher in males than in females.

KEYWORDS: Females, hypertension, males, population-based study, sex, sleep apnoea

$\mathbf{T}$ he association between obstructive sleep apnoea (OSA) and hypertension (HT) is an issue of increasing concern $[1,2]$. A substantial proportion of the adult population has mild-to-moderate OSA characterised by repeated episodes of apnoea and hypopnoea during sleep [3]. The prevalence of daytime HT has been estimated to include $50-60 \%$ of patients with known OSA [4]. Conversely, OSA has been reported in $>30 \%$ of HT patients [5] and may be a frequent cause of drug-resistant HT [6]. The reciprocal association between the two conditions advocates that OSA and HT may share common pathogenetical pathways. However, OSA appears to promote HT development [7] and to sustain a condition with elevated blood pressure [8]. Random controlled intervention trials of nasal continuous airway pressure in OSA patients demonstrated a reduction of blood pressure over a period of 4-9 weeks $[9,10]$.

Studies investigating the potential pathophysiological mechanisms involved in HT development in OSA have proposed the involvement of an increased peripheral vascular resistance [11].
Potential mediators include an increased sympathetic activity $[12,13]$, impaired reninangiotensin-aldosterone system function $[14,15]$ and endothelial dysfunction [16, 17]. Moreover, the repeated episodes of hypoxia/re-oxygenation in moderate-to-severe OSA may promote vascular inflammation [18], oxidative stress [19] and accelerate the development of atherosclerosis [20]. The exact influence of genotypical or phenotypical characteristics on the susceptibility to HT in OSA is still unclear [21-23]. OSA may represent a synergistic risk factor for HT development in certain subjects with, for example, comorbid obesity [24], a metabolic disease [25] or certain coexisting traditional risk factors [26]. Similarly, this risk may be different in males compared with females, due to a differential riskfactor pattern between the sexes.

Previous data investigating HT prevalence in sleep-laboratory $[27,28]$ and population- $[29,30]$ based cohorts, suggest that the risk of HT is essentially equal in male and female subjects with OSA. However, data on cardiovascular mortality [31], as well as recent experimental data on

\section{AFFILIATIONS}

*Sleep Laboratory, Dept of

Pulmonary Medicine, Sahlgrenska University Hospital, Gothenburg,

\# Skaraborg Institute, Skövde, and

'Dept of Clinical Sciences,

Community Medicine, Malmö

University Hospital, Malmö, Sweden.

CORRESPONDENCE

U. Lindblad

Lund University

Dept of Clinical Sciences

Community Medicine

Malmö University Hospital

SE 20502 Malmö

Sweden

Fax: 4640332615

E-mail: ulf.lindblad@med.lu.se

Received:

April 082005

Accepted after revision:

November 012005
European Respiratory Journal Print ISSN 0903-1936 Online ISSN 1399-3003 
endothelial function in sleep apnoea patients, suggested a differential impact in males and females [32].

The primary aim of the present case-control study was to explore OSA as a risk factor for HT in two community-based samples; patients with HT treated in primary care (cases) and normotensive subjects from a random population sample (controls). An additional aim of the study was to investigate the influence of sex on this association.

\section{SUBJECTS AND METHODS \\ Skaraborg Hypertension and Diabetes Project}

The Skaraborg Hypertension and Diabetes Project was originally launched with the goal to improve blood pressure control in the community. More specifically it was designed to assess the association between HT and type- 2 diabetes, with specific emphasis on the interaction between life-style and genetics. The Skara Primary Health Care Centre (Skara, Sweden) is the only available public primary healthcare facility in Skara, a community with $\sim 18,000$ inhabitants. Practically all the residents with HT and/or type- 2 diabetes were continuously surveyed including annual follow-ups at this centre. The baseline examination included all patients with HT and diabetes $(n=1,149)$ aiming to investigate the phenotypical and genotypical characteristics in subgroups of these conditions. This structured survey, enrolling patients consecutively seen at the primary healthcare centre between 1992 and 1993 [33], included: 1) a standardised medical history; 2) questionnaires regarding lifestyle; 3 ) anthropometric measures; and 4) a physical examination, which included blood pressure and blood sampling for metabolic and genetic characteristics. An adjacent population survey, stratified by age and sex, was then conducted in Skara between 1993-1994. Subjects $\geqslant 40$-yrs old were invited to the same outpatient clinic for a health control following the same protocol that was used for the HT and/or type-2 diabetes patients. For each 10-yr category between 40 79 yrs, 150 males and females were randomly selected from the population census register. In the ages $\geqslant 80 \mathrm{yrs}, 100$ males and 100 females were selected [34]. From this reference population, with an $80 \%$ response and participation rate, 1,109 subjects attended the clinic for investigation.

\section{Initial classification of blood pressure, anthropometrics, hypertension and diabetes}

Blood pressure was determined in the supine position after a 5min rest using a Tricuff (Pressure Group AB, Stockholm, Sweden), placed on the right arm at heart level and automatically adjusted for cuff size, and again 1 min later in the standing position. Body weight and height were determined to the nearest $0.1 \mathrm{~kg}$ and $\mathrm{cm}$, respectively. Waist and hip circumferences were measured to the nearest $\mathrm{cm}$ and the waist-hip ratio (WHR) was calculated. HT was diagnosed according to the contemporary (1992-1993) National Swedish guidelines [35], based on three consecutive blood pressure readings in the supine position $\geqslant 160 \mathrm{mmHg}$ (systolic pressure) and/or $90 \mathrm{mmHg}$ (diastolic pressure) and/or ongoing antihypertensive medication.

\section{The Skaraborg Sleep Study subjects}

The present study used a case-control design aimed at including 100 male and 100 female patients with HT from the surveyed population, with a corresponding number of population controls previously classified as normotensive. All control subjects with known HT at baseline $(n=60)$ or with newly developed HT $(n=46)$ were excluded from the control sample. However, the vast majority of those with known HT at baseline were already included in the patient sample. Participants from the two cohorts, aged $40-65$ yrs at baseline, were invited to undergo a full-night ambulatory polysomnography (PSG). Those responding to the invitation were seen in random order for informed consent at the primary care centre (study visit see below). Entry criteria for control subjects included a baseline blood pressure $<160 /<90 \mathrm{mmHg}$. When all eligible patients with HT had been considered for participation and a corresponding number of control individuals had been included the recruitment was stopped. Subjects fulfilling criteria subsequently underwent PSG. The recruitment process is summarised in figure 1. From the 290 invited patients with HT, 163 (56\%) were included. Of the 293 invited controls 185 (63\%) were finally enrolled. Descriptive characteristics of the study populations are shown in table 1. The Skaraborg Sleep Study was reviewed and approved by the local human research ethics review board.

\section{Study visit}

The study visit took place at the Skara Primary Health Care Centre primary and included a nurse-supervised assessment of blood pressure and registration of weight and height. Participants were interviewed for an updated medical history, including current intake of antihypertensive medication. All participants completed questionnaires relating to symptoms of sleep-disordered breathing [36], daytime sleepiness (Epworth Sleepiness Scale) [37] and quality of life (a 36-item short-form health survey) [38] prior to the PSG recording.

\section{Polysomnography measurement}

A full-night (minimum $8 \mathrm{~h}$ ) PSG recording using the Embla A10 system (Flaga, Reykjavik, Iceland) was scheduled within 14 days of the study visit. A specifically trained nurse attached all the electrodes and monitoring equipment required. Each recording included an electroencephalogram $\left(\mathrm{C}_{4} / \mathrm{A} 1, \mathrm{C}_{3} / \mathrm{A} 2\right.$, $\mathrm{C} z / \mathrm{A} 1$ ), electrooculogram, submental and tibials electromyograms, and electrocardiogram. Ventilatory monitoring included position sensor, oxygen saturation via an oximeter probe, respiratory movements via chest and abdominal belts, nasal and oral airflow via a thermistor, and nasal pressure via a standard nasal cannula. The PSG equipment was applied at the health centre between $18.00-21.00 \mathrm{~h}$ and all sleep recordings took place in the patients home environment. Technical problems resulting in insufficient data for PSG scoring were encountered in four cases.

All PSG recordings were manually scored by a sleep technician using international criteria for breathing disorders [39] and sleep [40]. An obstructive apnoea/hypopnoea event $(\geqslant 10 \mathrm{~s}$ duration) was defined as a $>50 \%$ amplitude reduction of airflow compared with baseline or an evident airflow reduction associated with either an oxygen desaturation of $>3 \%$ or an arousal. An oxygen desaturation event was defined as $\geqslant 3 \%$ oxyhaemoglobin decrease in the pulse oximeter recording. The apnoea-plus-hypopnoea index (AHI) and the oxygen desaturation index were determined as number of events per hour of sleep. In the current study, the presence of sleep apnoea was 


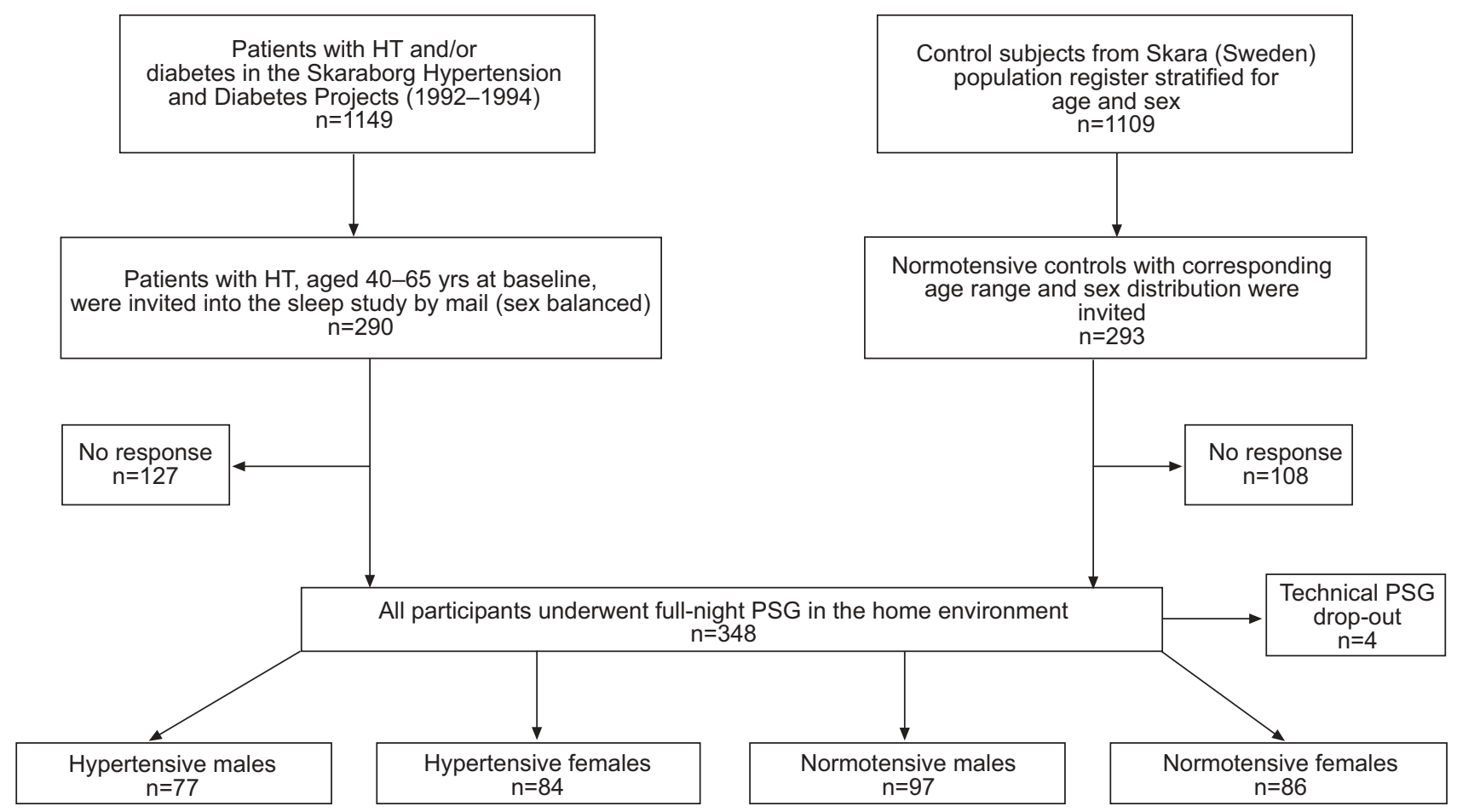

FIGURE 1. Flow chart displaying the selection undertaken for the study population. HT: hypertension; PSG: polysomnography.

\begin{tabular}{|c|c|c|c|c|}
\hline \multirow[t]{3}{*}{ TABLE 1} & \multicolumn{4}{|c|}{$\begin{array}{l}\text { Baseline characteristics of hypertensive }(\mathrm{HT}) \text { and } \\
\text { non-hypertensive (non-HT) males and females }\end{array}$} \\
\hline & \multicolumn{2}{|c|}{ Males } & \multicolumn{2}{|c|}{ Females } \\
\hline & HT & non-HT & Hт & non-HT \\
\hline Subjects $n$ & 77 & 97 & 84 & 86 \\
\hline Age yrs & $62(0.7)$ & $59(0.6)$ & $64(0.7)$ & $60(0.7)$ \\
\hline SBP $\mathrm{mmHg}$ & $148(1.7)$ & $132(1.5)$ & $150(1.6)$ & $133(1.6)$ \\
\hline DBP mmHg & $83(1.1)$ & $76(0.5)$ & $82(0.9)$ & $75(0.8)$ \\
\hline $\mathrm{BMI} \mathbf{k g} \cdot \mathrm{m}^{-2}$ & $29.6(4.5)$ & 26.7 (3.0) & $30.3(0.6)$ & $28.2(0.6)$ \\
\hline WHR & $0.96(0.006)$ & $0.93(0.005)$ & $0.86(0.007)$ & $0.83(0.007)$ \\
\hline AHI events $\cdot h^{-1}$ & $34(2.6)$ & $23(2.4)$ & $23(2.6)$ & $24(2.5)$ \\
\hline ODI events $\cdot h^{-1}$ & $18(1.4)$ & $14(1.8)$ & $13(1.7)$ & $13(1.7)$ \\
\hline TST min & $348(8.1)$ & 381 (7.2) & $365(7.9)$ & 389 (7.8) \\
\hline OSmin \% & $81(0.8)$ & $82(0.8)$ & $82(0.7)$ & $82(0.7)$ \\
\hline
\end{tabular}

Data are presented as mean (SE). SBP: systolic blood pressure; DBP: diastolic blood pressure; BMI: body mass index; WHR: waist-hip ratio; AHI: apnoeaplus-hypopnoea index; ODI: oxygen destauration index; TST: total sleep time; OSmin: minimum oxygen saturation reached during the night recording.

assessed by using two different cut-off levels. The cut-off of AHI 10 was chosen to represent mild OSA while the AHI 30 cut-off represents severe OSA.

\section{Statistics}

All analyses were adjusted for age and stratified by sex if not specified. Association between categorical variables were analysed by logistic regression and expressed in odds ratios (OR) with 95\% confidence intervals (CI). Differences in means between groups were analysed by ANCOVA. The sex difference in the association between OSA and HT was investigated by a two-way interaction term (OSA $\times$ sex) in a logistic regression model with $\mathrm{HT}$ as the dependent variable and with age, OSA, and sex as covariates. All tests were twosided and statistical significance was assumed when $\mathrm{p}<0.05$.

\section{RESULTS}

OSA was highly prevalent in these middle-aged to elderly study participants. The AHI levels and OSA prevalence were generally higher in males than in females (table 1 and 2). Overall AHI expressed as mean \pm SE was $34 \pm 2.6$ and $23 \pm 2.4$ events $\cdot \mathrm{h}^{-1}$ in hypertensive and normotensive males, respectively $(p=0.004)$. In contrast, the AHI levels in the two female groups were $23 \pm 2.6$ and $24 \pm 2.5$, respectively $(p=0.759)$. As seen in table 1, hypertensives of either sex tended to be older, more obese and to have a higher WHR when compared with their normotensive counterparts. Blood pressures were almost identical in males and females in both the hypertensive and the normotensive groups. Total sleep time was generally shorter in hypertensives of either sex.

The proportion of males with OSA, using either AHI 10 or 30 events $\cdot h^{-1}$ as the cut-off for diagnosis, was significantly higher in HT subjects than in the controls (table 2). This difference was not seen in the females. A formal test of a differential effect by sex in the association between OSA and HT by a two-way interaction term (OSA $\times$ sex) was nonsignificant (2.2 (0.8-6.0); $\mathrm{p}=0.124)$. The OR for HT was unaffected by AHI severity threshold (10 or 30) in males, while AHI, by either threshold, was not associated with HT in females. In both sexes body mass index (BMI) was associated with HT $(p<0.001$ in males and $\mathrm{p}=0.018$ in females), and a corresponding ageindependent association was seen between BMI and OSA $(p=0.007$ in males and $p=0.004$ in females). 


\begin{tabular}{|c|c|c|c|c|c|c|}
\hline TABLE 2 & $\begin{array}{l}\text { Associ } \\
\text { (OSA) } \\
\text { female } \\
\text { (AHI) } 1\end{array}$ & $\begin{array}{l}\text { is b } \\
\text { hyp } \\
\text { ing } \\
\text { hd } 3\end{array}$ & $\begin{array}{l}\text { een ob } \\
\text { nsion } \\
\text { oea-pl } \\
\text { vents.h }\end{array}$ & $\begin{array}{l}\text { ictive } \\
\text { in r } \\
\text { nypo } \\
\text { s the }\end{array}$ & $\begin{array}{l}\text { leep ap } \\
\text { ales anc } \\
\text { noea inc } \\
\text { cut-off }\end{array}$ & $\begin{array}{l}\text { onoea } \\
\text { dex } \\
\text { alue }\end{array}$ \\
\hline \multirow{2}{*}{$\begin{array}{l}\text { OSA } \\
\text { categories }\end{array}$} & \multicolumn{2}{|c|}{ Controls } & \multicolumn{4}{|c|}{ HT } \\
\hline & n (\%) & OR & n (\%) & OR & $95 \% \mathrm{Cl}$ & $p$-value \\
\hline \multicolumn{7}{|l|}{ Males } \\
\hline$A H I \geqslant 10$ & $62(64)$ & 1 & $64(83)$ & 2.9 & $1.4-6.2$ & 0.005 \\
\hline$A H I \geqslant 30$ & $24(25)$ & 1 & $36(47)$ & 2.6 & $1.4-5.1$ & 0.004 \\
\hline \multicolumn{7}{|l|}{ Females } \\
\hline$A H I \geqslant 10$ & $49(57)$ & 1 & 58 (69) & 1.3 & $0.7-2.6$ & 0.408 \\
\hline$A H I \geqslant 30$ & $21(24)$ & 1 & $22(26)$ & 0.7 & $0.3-1.6$ & 0.417 \\
\hline
\end{tabular}

OR: odds ratio; $95 \% \mathrm{Cl}$ : 95\% confidence intervals. Age-adjusted associations were estimated with logistic regression and presented as OR with 95\% Cl

There was a dose-response relationship between AHI categorised in tertiles and HT in males (fig. 2). The OR for HT increased across AHI tertiles from 1.0 to 2.1 (95\% CI: 0.9-4.5)
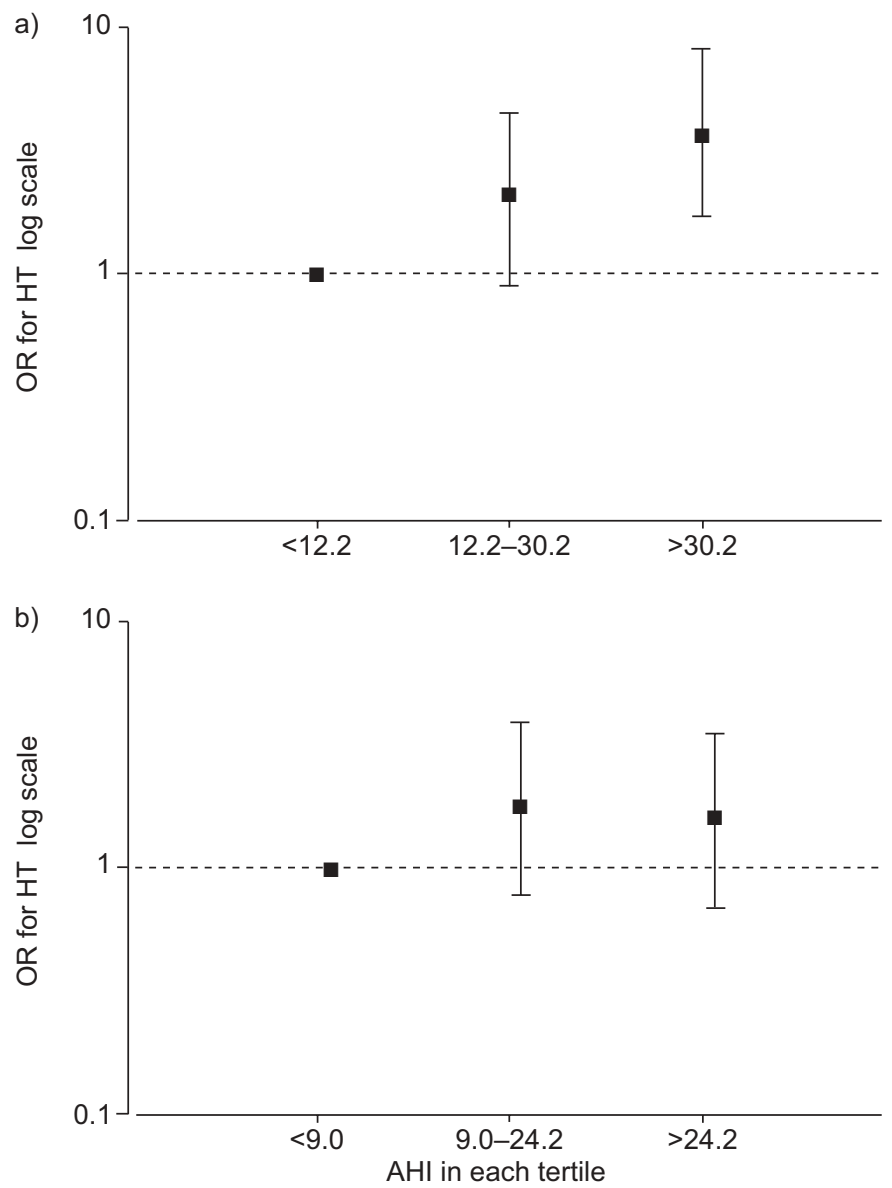

FIGURE 2. Odds ratio (OR) for hypertension $(\mathrm{HT})$ in a) males and b) females divided in tertiles of apnoea-plus-hypopnoea index (AHI) severity. The AHI severity within tertiles is indicated. - - -: an OR of 1.0 for the reference group (tertile one) to facilitate comparisons with tertile two and three, respectively. and from 1.0 to 3.7 (95\% CI: 1.7-8.2) in males (p-value for trend was 0.005$)$, but not in females where the OR increased from 1.0 to 1.8 (95\% CI: $0.8-3.9$ ) and from 1.0 to 1.6 (95\% CI: $0.7-3.5$; $\mathrm{p}$-value for trend was 0.310$)$. In a logistic regression analysis of the association between OSA (AHI $\geqslant 10$ events $\cdot h^{-1}$ ) and HT, adjustment for differences in age and BMI resulted in a moderate weakening of the OR in males to 2.3 (95\% CI: $1.0-5.1$; $\mathrm{p}=0.043$ ). However, the association remained nonsignificant in females (table 3). Age and smoking had less of an influence. Factors related to the severity of overnight hypoxaemia had an insignificant influence (data not shown). Confounding from body composition was also accounted for by repeating analyses of associations between OSA and HT in strata of overall obesity (BMI World Health Organization-categories) and abdominal obesity (WHR $\geqslant 1.0$, or not). However, there was a consistent and remaining pattern suggesting an independent association between OSA and HT in males. All analyses were repeated after the exclusion of subjects with a total sleep time $<4 \mathrm{~h}(\mathrm{n}=22)$ and results were essentially unchanged.

\section{DISCUSSION}

The present study demonstrated that OSA is a highly prevalent phenomenon in these middle-aged to elderly cases of HT and population controls. An independent association between OSA and HT was confirmed and the association was confounded by, though independent of, body composition. However, there was a difference in risk between males and females suggesting that the susceptibility to HT development in OSA may be sex dependent and further studies should focus on this issue.

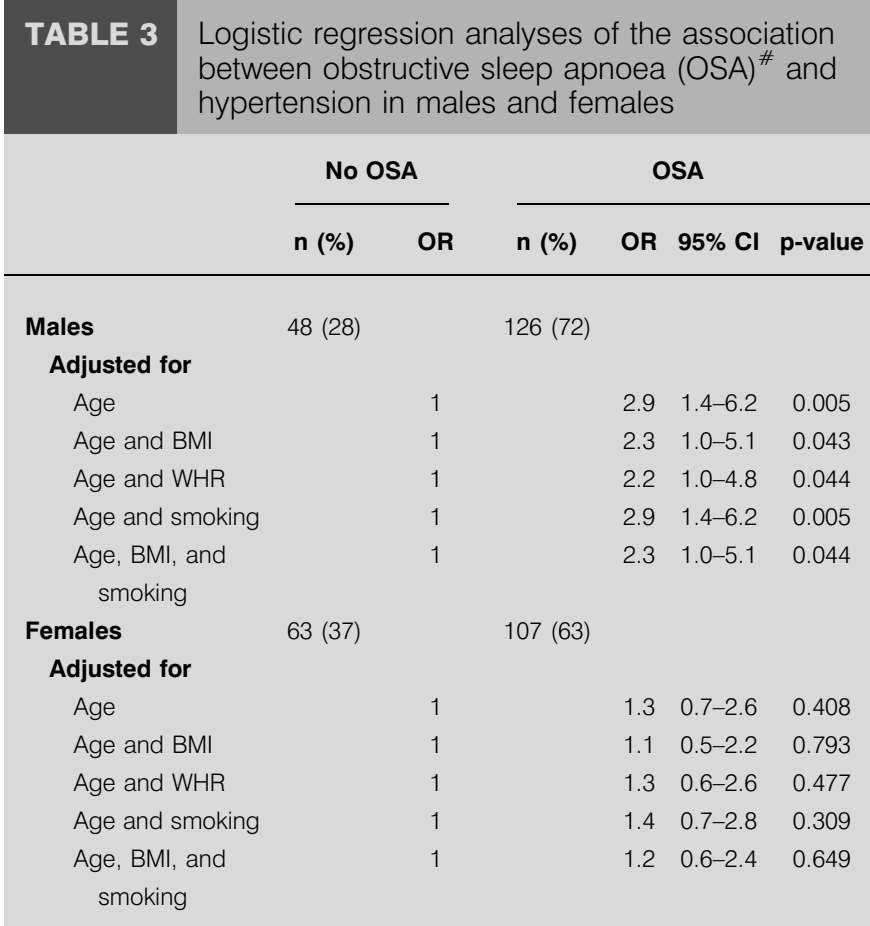

BMI: body mass index: WHR: waist-hip ratio; OR: odds ratio; $95 \% \mathrm{Cl}$ : 95\% confidence intervals. Associations were estimated with logistic regression and presented as OR with $95 \% \mathrm{Cl}$. \#: apnoea-plus-hypopnoea index $\geqslant 10$ events $\cdot h^{-1}$ 
The current study confirms two aspects of previous crosssectional population studies. First, unrecognised OSA was highly prevalent in the general population [3] and sleep apnoea was over-represented in subjects with a known HT diagnosis [41]. The individual awareness of OSA in the current population was low. In fact, only one subject, who enrolled in the study, had previously received medical attention for symptoms of sleep-disordered breathing. The average BMI of the current subjects were similar to that of several previous populations investigated in the same context, e.g. the Sleep Heart Health Study [30]. Yet, the prevalence of OSA appeared to be considerably higher. Methodological differences are likely to explain at least part of this discrepancy. The current study used both a nasal pressure cannula and a thermistor for assessment of oro/nasal airflow. This procedure has previously been demonstrated to result in a considerably higher calculated AHI in sleep studies [42]. The method is more sensitive at detecting sleep-disordered breathing, particularly in mild OSA. Therefore, a larger number of subjects with mild OSA are likely to have been identified in the current study.

Secondly, OSA was independently associated with HT. This association was valid irrespective of the cut-off level applied for diagnosis (AHI 10 or 30 events $\cdot h^{-1}$ ), suggesting that even a proportionally low intensity OSA was associated with an increased risk for HT. The overall OR for HT was in the same order of magnitude as that previously described in a sleep laboratory cohort [28], a population of middle-aged US state employees [7] or in the Sleep Heart Health Study cohort [30]. In contrast to the findings in any of these cohorts, the current study found that the association between OSA and HT was almost entirely restricted to the male sex. The current study had a case-control design and did not constitute a combined cohort study. Thus, the effect of OSA exposure in the cases was compared with that of the controls. By contrast, in the previous cohort trials, the analysis was based on the exposure of OSA and the effect on association with HT. Moreover, HT cases in the current study had been accumulated over an extensive time period and the HT diagnosis was evidently well established. It is, therefore, apparent that a different subset of HT sufferers was addressed in the present study. It cannot be excluded that the composition of the HT subset in the current study accounted for the lack of association between OSA and HT in females. However, previous studies investigating drug resistant HT [6, 8] have not pointed towards evident sex differences in the association between HT and OSA.

The current study differs from previous studies in several other important aspects. It was sex balanced and addressed an ethnically homogenous population. The female subjects were almost exclusively post-menopausal. This may have accounted for a proportionally higher number of females with OSA in the present study [43], and therefore, may have resulted in a dilution of the association between OSA and HT in females. However, the lack of an association in females should be interpreted with great caution. Not only were the age adjusted OR for OSA (AHI $\geqslant 10$ ), and the upper AHI tertile in females increased to 1.3 and 1.6, allowing for up to 2.6 and 3.5, respectively, but a formal interaction term was also nonsignificant, although again with a wide $95 \%$ CI. Although the effect seems to be smaller in females, the current findings indicate too low a power to conclusively rule out an association between OSA and HT in females. The high criteria for HT used in this study may also have contributed to a dilution of an existing association.

The current study has several strengths and weaknesses. The response rates for participation in the PSG surveys were $\sim 60 \%$, which should be considered as high, given the commitment required from the participants. However, it is not high enough to confidently exclude selection bias. This should be kept in mind when generalising the findings of this study. PSG data was acquired in a primary healthcare ambulatory setting. Results that were close to the complete set of recordings were technically acceptable for adequate sleep stage scoring. Elimination of the subset of subjects with a short total sleep time did not influence the principal results of the study. This procedure may be argued to have changed the validity of the sleep recordings, however, many studies have shown the similarity of in-lab PSG and home PSG $[44,45]$. A considerable proportion of the cases in this study were taking antihypertensive medications. However, HT was defined as a categorical variable in the current study's analysis. There is no evidence to suggest that antihypertensive medications would have affected the occurrence or severity of OSA differently [46]. The incomplete risk factor classification was a weakness of the current study. Traditional risk factors were thoroughly documented, but blood sampling was systematically performed only at the time of the original survey. Although, this does not provide a limitation in terms of investigating an association between OSA and HT it restricts the possibility to perform an evaluation of more recently identified confounder influences.

In conclusion, the current data confirms previous findings of an independent association between obstructive sleep apnoea and hypertension. This association was evident in males but not identifiable in these essentially post-menopausal females. The findings suggest a possible sex-dependent difference in susceptibility to hypertension development in sleepdisordered breathing. Due to the high prevalence of obstructive sleep apnoea in patients with hypertension, sleepdisordered breathing should be considered when patients with high blood pressure are evaluated in primary care.

\section{ACKNOWLEDGEMENTS}

The authors would like to thank A. Mehner, P. Murphy, H. Axelsson and A. Segerblom for their excellent technical and secretarial assistance.

\section{REFERENCES}

1 Hedner J, Grote L. The link between sleep apnea and cardiovascular disease: time to target the nonsleepy sleep apneics? Am J Respir Crit Care Med 2001; 163: 5-6.

2 Kiely JL, McNicholas WT. Cardiovascular risk factors in patients with obstructive sleep apnoea syndrome. Eur Respir J 2000; 16: 128-133.

3 Young T, Palta M, Dempsey J, Skatrud J, Weber S, Badr S. The occurrence of sleep-disordered breathing among middle-aged adults. N Engl J Med 1993; 328: 1230-1235.

4 Silverberg DS, Oksenberg A. Are sleep-related breathing disorders important contributing factors to the production 
of essential hypertension? Curr Hypertens Rep 2001; 3: 209-215.

5 Worsnop CJ, Naughton MT, Barter CE, Morgan TO, Anderson AI, Pierce RJ. The prevalence of obstructive sleep apnea in hypertensives. Am J Respir Crit Care Med 1998; 157: 111-115.

6 Logan AG, Perlikowski SM, Mente A, et al. High prevalence of unrecognized sleep apnoea in drug-resistant hypertension. J Hypertens 2001; 19: 2271-2277.

7 Peppard PE, Young T, Palta M, Skatrud J. Prospective study of the association between sleep-disordered breathing and hypertension. N Engl J Med 2000; 342: 1378-1384.

8 Lavie P, Hoffstein V. Sleep apnea syndrome: a possible contributing factor to resistant. Sleep 2001; 24: 721-725.

9 Pepperell JC, Ramdassingh-Dow S, Crosthwaite N, et al. Ambulatory blood pressure after therapeutic and subtherapeutic nasal continuous positive airway pressure for obstructive sleep apnoea: a randomised parallel trial. Lancet 2002; 359: 204-210.

10 Becker HF, Jerrentrup A, Ploch $\mathrm{T}$, et al. Effect of nasal continuous positive airway pressure treatment on blood pressure in patients with obstructive sleep apnea. Circulation 2003; 107: 68-73.

11 Fletcher EC. The relationship between systemic hypertension and obstructive sleep apnea: facts and theory. Am J Med 1995; 98: 118-128.

12 Hedner J, Ejnell H, Sellgren J, Hedner T, Wallin G. Is high and fluctuating muscle nerve sympathetic activity in the sleep apnoea syndrome of pathogenetic importance for the development of hypertension? J Hypertens 1988; 6: Suppl., S529-S531.

13 Narkiewicz K, van de Borne PJ, Cooley RL, Dyken ME, Somers VK. Sympathetic activity in obese subjects with and without obstructive sleep apnea. Circulation 1998; 98: 772-776.

14 Moller DS, Lind P, Strunge B, Pedersen EB. Abnormal vasoactive hormones and 24-hour blood pressure in obstructive sleep apnea. Am J Hypertens 2003; 16: 274-280.

15 Calhoun DA, Nishizaka MK, Zaman MA, Harding SM. Aldosterone excretion among subjects with resistant hypertension and symptoms of sleep apnea. Chest 2004; 125: $112-117$.

16 Carlson JT, Rangemark C, Hedner JA. Attenuated endothelium-dependent vascular relaxation in patients with sleep apnoea. J Hypertens 1996; 14: 577-584.

17 Ip MS, Tse HF, Lam B, Tsang KW, Lam WK. Endothelial function in obstructive sleep apnea and response to treatment. Am J Respir Crit Care Med 2004; 169: 348-353.

18 Shamsuzzaman AS, Winnicki M, Lanfranchi $\mathrm{P}$, et al. Elevated C-reactive protein in patients with obstructive sleep apnea. Circulation 2002; 105: 2462-2464.

19 Lavie L, Vishnevsky A, Lavie P. Evidence for lipid peroxidation in obstructive sleep apnea. Sleep 2004; 27: 123-128.

20 Dean RT, Wilcox I. Possible atherogenic effects of hypoxia during obstructive sleep apnea. Sleep 1993; 16: Suppl. 8, S15-S21; discussion S21-22.

21 Zhang J, Zhao B, Gesongluobu Sun Y, et al. Angiotensinconverting enzyme gene insertion/deletion (I/D) polymorphism in hypertensive patients with different degrees of obstructive sleep apnea. Hypertens Res 2000; 23: 407-411.
22 Barcelo A, Elorza MA, Barbe F, Santos C, Mayoralas LR, Agusti AG. Angiotensin converting enzyme in patients with sleep apnoea syndrome: plasma activity and gene polymorphisms. Eur Respir J 2001; 17: 728-732.

23 Lin L, Finn L, Zhang J, Young T, Mignot E. Angiotensinconverting enzyme, sleep-disordered breathing, and hypertension. Am J Respir Crit Care Med 2004; 170: 1349-1353.

24 Kiselak J, Clark M, Pera V, Rosenberg C, Redline S. The association between hypertension and sleep apnea in obese patients. Chest 1993; 104: 775-780.

25 Coughlin SR, Mawdsley L, Mugarza JA, Calverley PM, Wilding JP. Obstructive sleep apnoea is independently associated with an increased prevalence of metabolic syndrome. Eur Heart J 2004; 25: 735-741.

26 Wetter DW, Young TB, Bidwell TR, Badr MS, Palta M. Smoking as a risk factor for sleep-disordered breathing. Arch Intern Med 1994; 154: 2219-2224.

27 Grote L, Ploch T, Heitmann J, Knaack L, Penzel T, Peter JH. Sleep-related breathing disorder is an independent risk factor for systemic hypertension. Am J Respir Crit Care Med 1999; 160: 1875-1882.

28 Lavie P, Herer P, Hoffstein V. Obstructive sleep apnoea syndrome as a risk factor for hypertension: population study. BMJ 2000; 320: 479-482.

29 Young T, Peppard P, Palta M, et al. Population-based study of sleep-disordered breathing as a risk factor for hypertension. Arch Intern Med 1997; 157: 1746-1752.

30 Nieto FJ, Young TB, Lind BK, et al. Association of sleepdisordered breathing, sleep apnea, and hypertension in a large community-based study. Sleep Heart Health Study. JAMA 2000; 283: 1829-1836.

31 Young T, Finn L. Epidemiological insights into the public health burden of sleep disordered breathing: sex differences in survival among sleep clinic patients. Thorax 1998; 53, Suppl. 3, S16-S19.

32 Faulx MD, Larkin EK, Hoit BD, Aylor JE, Wright AT, Redline S. Sex influences endothelial function in sleepdisordered breathing. Sleep 2004; 27: 1113-1120.

33 Bog-Hansen E, Lindblad U, Bengtsson K, Ranstam J, Melander A, Rastam L. Risk factor clustering in patients with hypertension and non-insulin-dependent diabetes mellitus. The Skaraborg Hypertension Project. J Intern Med 1998; 243: 223-232.

34 Ostgren CJ, Lindblad U, Ranstam J, Melander A, Rastam L. Associations between smoking and beta-cell function in a non-hypertensive and non-diabetic population. Skaraborg Hypertension and Diabetes Project. Diabet Med 2000; 17: 445-450.

35 Medical Products Agency. Treatment Of Hypertension In The Elderly. Stockholm, Medical Products Agency, 1993.

36 Gislason T, Almqvist M, Eriksson G, Taube A, Boman G. Prevalence of sleep apnea syndrome among Swedish men--an epidemiological study. J Clin Epidemiol 1988; 41 571-576.

37 Johns MW. A new method for measuring daytime sleepiness: the Epworth sleepiness scale. Sleep 1991; 14: 540-545.

38 Ware JE Jr, Sherbourne CD. The MOS 36-item short-form health survey (SF-36). I. Conceptual framework and item selection. Med Care 1992; 30: 473-483. 
39 Sleep-related breathing disorders in adults: recommendations for syndrome definition and measurement techniques in clinical research. The Report of an American Academy of Sleep Medicine Task Force. Sleep 1999; 22: 667-689.

40 Rechtschaffen A, Kales A. A manual of standardized terminology, techniques and scoring system for sleep stages of human subjects. Bethesda, Maryland, U.S. Department of Health, Education, and Welfare Public Health service - National Institutes of Health, 1968.

41 Kales A, Bixler EO, Cadieux RJ, et al. Sleep apnoea in a hypertensive population. Lancet 1984; 2: 1005-1008.

42 Teichtahl H, Cunnington D, Cherry G, Wang D. Scoring polysomnography respiratory events: the utility of nasal pressure and oro-nasal thermal sensor recordings. Sleep Med 2003; 4: 419-425.
43 Young T, Finn L, Austin D, Peterson A. Menopausal status and sleep-disordered breathing in the Wisconsin Sleep Cohort Study. Am J Respir Crit Care Med 2003; 167: 1181-1185.

44 Fry JM, DiPhillipo MA, Curran K, Goldberg R, Baran AS. Full polysomnography in the home. Sleep 1998; 21: 635-642.

45 Iber C, Redline S, Kaplan Gilpin AM, et al. Polysomnography performed in the unattended home versus the attended laboratory setting-Sleep Heart Health Study methodology. Sleep 2004; 27: 536-540.

46 Kraiczi H, Hedner J, Peker Y, Grote L. Comparison of atenolol, amlodipine, enalapril, hydrochlorothiazide, and losartan for antihypertensive treatment in patients with obstructive sleep apnea. Am J Respir Crit Care Med 2000; 161: 1423-1428. 